https://www.interface.org.br

eISSN 1807-5762

\title{
Debates
}

\section{Saberes transformam práticas}

\author{
Knowledge changes practices \\ Saberes transforman las prácticas
}

Helena Maria Scherlowski Leal David(a)

<helenad@uerj.br> iD (a) Departamento de Enfermagem de Saúde Pública, Faculdade de Enfermagem, Universidade do Estado do Rio de Janeiro. Boulevard 28 de Setembro, 157, 70 andar, Vila Isabel. Rio de Janeiro, RJ, Brasil. 20551-030.

O texto de José Ivo Pedrosa apresenta, em breves linhas, marcos relevantes da história do campo da Educação Popular em Saúde (EPS). Vale iniciar este debate com breve digressão a respeito desse termo, originalmente usando o conectivo "e" e não a preposição "em", mais utilizada com referência ao mesmo processo histórico, inclusive adotada no título da Política Nacional de Educação Popular em Saúde (PNEPS-SUS). Porém, as reflexões coletivas iniciais que dispararam o processo de construção de açôes a serem pautadas por uma política de Estado expressaram ideia de articulação entre dois campos, uma forma de ressaltar que a base do processo é a Educação Popular como campo de expressão de resistências, lutas e forças que "traz a preocupação de incorporar, nas políticas e práticas de saúde, o conhecimento das pessoas comuns”’ (p. 7), superando a concepção da Educação em Saúde como responsabilidade exclusiva dos profissionais de saúde. A Educação Popular olha e quer contribuir com novos modos de fazer Saúde. Tratava-se, também, de se contrapor à utilização do termo Educação em Saúde, pouco problematizado no cotidiano dos serviços e práticas, e muito usado dentro de uma perspectiva instrumental de educação. 
Destaco o que parece ser um preciosismo gramatical sem importância para colocar uma questão que permeia o texto de Pedrosa, e que tem consequências concretas: em que reside o "popular" da Educação Popular em Saúde (EPS)?

Na produção desse campo, há um posicionamento não apenas pedagógico, mas também epistemológico e ético-político, sustentado por fazeres e práticas situadas na luta histórica contra a opressão e a invisibilização das diversas culturas e saberes. Porém, como esse "produto" tem sido incorporado nas práticas de saúde e nas políticas que garantem essas práticas? Na perspectiva de convergência de formas de resistência e luta, de afirmação de identidades e da diversidade de saberes, há que se perguntar se o entendimento acerca da radicalidade da proposta da EPS tem sido efetivamente compreendido e posto em prática no setor Saúde, um campo no qual o saber técnicocientífico é ainda hegemônico.

Não é raro que práticas autointituladas de Educação Popular estejam na verdade centradas na busca de formas diferentes de fazer Educação, restritas à dimensão metodológica. É como que se fazer EPS pudesse ser apenas um modo "mais alegre” e "informal" de educar, incorporando linguagens e expressóes artísticas como teatro e música, de fora para dentro. Vale ressaltar que não se trata de negar ou desqualificar as diversas formas de expressão da cultura popular na sua potência de fazer convergir sentidos e criar novas compreensóes do mundo, capazes de fortalecer e manter fortes as pessoas dos grupos subalternizados e vulnerabilizados. Pelo contrário, a crítica dirige-se às propostas que visam expropriar esses grupos de seus saberes e expressões culturais para mimetizar uma ideia estereotipada de "popular", o que às vezes é feito de forma ingênua e acrítica. Por isso mesmo, trouxemos o termo "informal" entre aspas, reforçando a compreensão sobre uma educação popular que se produz no cotidiano dos modos de viver, que ultrapassa e está fora da formalidade, das fôrmas e dos formatos do ensino institucionalizado.

Claro está que não há um único modo de educar, e que a EPS não é exclusiva ou propriedade de nenhum grupo ou coletivo. Por outro lado, dependendo de quem assume a condução do processo em cada local, há o risco de que se reduza a uma forma de expropriação, uma perspectiva que apenas nomeie como EPS um fazer acrítico, sem historicidade e desenraizado da realidade local, que pode acabar reproduzindo práticas educativas prescritivas tradicionais, e servir, em última análise, a uma ordem social que naturaliza a injustiça e não explicita as contradiçóes e os projetos em disputa. O que queremos afirmar é que a institucionalização da PNEPS pode-se dar em espaços diversos, alinhados ou não às lutas e demandas populares. É exatamente por isso que, como muitas vezes ouvimos Pedrosa comentar, nem toda ação educativa que se intitula de popular o é, assim como muitas iniciativas que não se autonomeiam de EP o são.

Cabe, portanto, somar ao texto de Pedrosa algumas perguntas a respeito dos limites e potencialidades da institucionalização da EPS. O momento crucial (no sentido de encruzilhada e escolha de caminhos), que foi o processo de disputa e eleição de Luís Inácio Lula da Silva à presidência, deixou pistas para essa reflexão. Nesse período foi constituída a Articulação Nacional de Movimentos e Práticas de EPS (Aneps), que nas suas bases operativas se propôs um movimento horizontal, com clara demarcação política por meio da qual pretendia agir: 
Por vivermos numa sociedade de classes que é histórica, onde as posições dos diferentes grupos sociais estão sempre se modificando umas relativamente às outras, é importante reconhecer que os saberes alteram as práticas e o fundamental, do ponto de vista da educação popular, é lutar pela transformação da sociedade, pela afirmação dos sujeitos e, portanto, respeitar as diferenças, saber escutar e reconhecer ${ }^{1}$. (p. 3)

Nesse parágrafo estão contidas as bases e as contradiçôes que vêm historicamente produzindo avanços e retrocessos, às vezes retrocessos dentro dos avanços, no movimento de EPS.

Há que se considerar que as opçóes quanto aos caminhos e às prioridades, sobretudo diante dos limites de recursos que pudessem financiar ações de mobilização, de formação, materiais educativos, entre outros, demandaram decisões estratégicas dentro da PNEPS. Foi necessário um certo "ter de dançar conforme a música" ao mesmo tempo em que se buscou fazer avançar projetos para ampliar o alcance da PNEPS. Indagamos em que medida essas opçôes estratégicas drenaram energias que, historicamente no movimento de EPS, se constituíam em açôes diretas, cotidianas e radicais, oriundas das agendas locais - dos serviços, territórios, comunidades, movimentos.

Apesar de os projetos institucionais, em especial os de formação, serem pautados por metodologias pedagógicas participativas e fortalecedoras dos sujeitos populares, é preciso indagar se não ocorreu alguma perda da capacidade da EPS como movimento de saúde para a escuta, o diálogo e a politização do debate sobre o direito à saúde com os grupos das classes populares no nível local, dos territórios. São indagações que vieram se produzindo pela constatação dos companheiros da EPS de um certo desequilíbrio entre a agenda de demandas institucionais (congressos acadêmicos, seminários governamentais), bastante intensa em muitos momentos ainda que pontuais, e a nossa capacidade de continuar com as interlocuçóes e construçôes locais, com grupos menores e educadores populares das comunidades, de forma sistemática, processual e cotidiana.

Não faz muito tempo, eu e José Ivo Pedrosa nos dirigíamos, em um transporte por aplicativo, para uma atividade na Universidade Estadual do Ceará, e isso ocorreu justamente na semana em que o ex-presidente Lula havia sido preso. Enquanto íamos discutindo a conjuntura política, notamos que o jovem motorista ia acompanhando interessado a conversa, até que, vencida a timidez, nos dirigiu, envergonhadamente, uma pergunta: "Vocês que são professores, poderiam me explicar algo que ninguém nunca me explicou - o que é isso de esquerda e direita que tanto falam na política?”. Foi uma situação que nos despertou questóes a respeito de que tipo de debate político e coletivo está sendo oportunizado às pessoas das classes populares? Além de trabalhar para sobreviver, que oportunidades de reflexão e troca a respeito das lutas pela saúde e pela vida digna existem hoje?

É preciso que nos perguntemos acerca dos limites e possibilidades de uma política de EPS, pois as regras do jogo político na relação entre movimentos, academia, serviços e governos não são as mesmas. 
Há um descompasso entre o conhecimento acumulado na trajetória da EPS e a nossa capacidade hoje de gerar debates com efetiva participação popular. Por um lado, há maturidade na reflexão coletiva expressa na crescente produção acadêmica, e um aumento da visibilidade da própria EPS dentro dos espaços acadêmicos e institucionais da saúde. Por outro lado, nota-se que os grupos e coletivos envolvidos ampliaram seus quadros com a adesão de estudantes e profissionais, porém os debates tendem a se pulverizar em torno de agendas diversas, de relevância indiscutível, mas que não convergem para a análise coletiva das contradições para a reprodução social da classe trabalhadora, cada vez mais desmobilizada e fragilizada. Lembrando da crítica de Eymard Vasconcelos ${ }^{2}$ às formas de educar tradicionais, há um novo "fosso cultural” entre serviços, academia e população?

Se "saberes alteram as práticas", conforme explicitado na intencionalidade do campo da EPS diante do alvorecer de um governo de caráter democrático e popular, nos idos de 2003, que saberes e práticas se fazem necessários, hoje, para superar distâncias e efetivar novos pactos capazes de defender e garantir o direito à saúde?

Essas e outras indagaçóes precisam, agora e doravante, guiar nossas açôes em cada espaço onde estamos, pessoas da EPS no exercício de um fazer pedagógico em saúde que seja também explicitamente político, que tome posição em favor dos princípios de justiça social e direitos. É hora de radicalizar, de chegar à raiz da prática pedagógica pautada no diálogo e na ideia de emancipação, aceitando mais uma vez o convite de Paulo Freire 3 : dispamo-nos, fiquemos nus, e recomecemos a nos vestir de povo.

\section{Conflito de interesse}

A autora não tem conflito de interesse a declarar.

\section{Direitos autorais}

Este artigo está licenciado sob a Licença Internacional Creative Commons 4.0, tipo BY (https://creativecommons.org/licenses/by/4.0/deed.pt_BR)

\section{(cc) BY}

\section{Editor}

Antonio Pithon Cyrino

Editor associado

Pedro José Santos Carneiro Cruz

\section{Submetido em}

27/07/20

Aprovado em

$11 / 09 / 20$ 
(2)

\section{Referências}

1. Articulação Nacional de Movimentos e Práticas de Educação Popular e Saúde ANEPS. O caminho das águas em 2003. Brasília: Ministério da Saúde; 2003.

2. Vasconcelos EM. Espiritualidade na educação popular em saúde. Cad CEDES. 2009; 29(79):323-33.

3. Freire P. Pedagogia da esperança. 12a ed. São Paulo: Paz e Terra; 2005. 